\title{
The illusion of gender parity
}

To the Editor - I am glad the article "Gender imbalance in US geoscience academia” (Nature Geosci. 1, 79-82; 2008) featured so prominently in your new journal. However, I must take issue with the authors' definition of gender parity for the geosciences: "A department will have achieved gender parity when every student in it can look at the faculty and see at least one person whose life they wish to emulate. A department with only one woman or with five childless female full professors is not there yet."

So the authors want to ensure that young women know they can have children and an academic career, and that they can see this reflected in the success of the professors they interact with on a daily basis. Yet within my corner of the earth sciences 'blogosphere' I have seen women coming close to breaking point trying to juggle their family and their career. One post I read on a blog by "Sciencewoman" concluded: "So for any of you who want to hold me up as an example that we can do it all and it is possible, please don't give me that burden too. My plate's already a little full."

If gender parity is a department with three or so female assistant professors suffering like Sciencewoman, with students oblivious to what it's really like, then gender parity is frankly unappealing. If gender parity is a department in which female professors with children are no more stressed than their male and childless female colleagues, then I doubt this will be achieved in my lifetime.

Women are still having to choose between a family and a career, and I hope this article will be a wake-up call to the brain-drain occurring beyond postgraduate level.

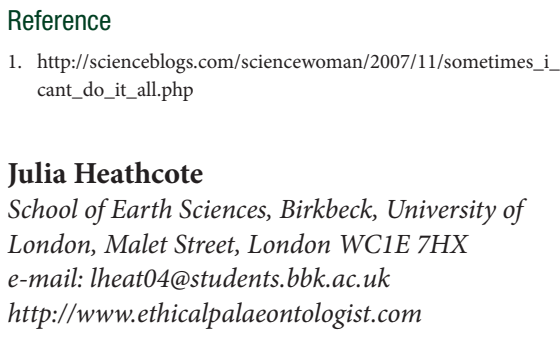

Julia Heathcote

School of Earth Sciences, Birkbeck, University of London, Malet Street, London WC1E 7HX

e-mail: Theat04@students.bbk.ac.uk

http://www.ethicalpalaeontologist.com

\section{Expectations and gender imbalance}

To the Editor - The Feature by Holmes et al. (Nature Geosci. 1, 79-82; 2008) provides important data and observations about the low percentages of women professors in academic geoscience. However, there may be other explanations than those given by the focus groups.

The best explanation for what I've observed (as a female associate professor) comes from the gender schemas work of Virginia Valian, a cognitive scientist at Hunter College. The basic idea is that people's expectations influence their perceptions of others (and of themselves), and these little differences in perception add up. So the statements about "intrinsic female attributes" mentioned by the focus groups (such as "women are choosing a different career path," "females don't like field work," "females in general have a low interest in the subject matter," "females lack self-confidence," and "females in general prefer to teach") are the problems in themselves. Even when they aren't true about a particular job applicant (or woman coming up for tenure, or grant applicant, or paper author, or woman who is not even nominated for a Young Scientist award), the expectation that they will be true influences the people making the judgments.

The structural issues are real. Yes, it is incredibly difficult to juggle a small child and new teaching and research responsibilities. But it is even harder when you've also got to disprove flawed hypotheses ("she was only a courtesy co-author on that paper"; "she doesn't want to do field work"; "she is more interested in teaching than research.").

Changing the tenure clock to accommodate childbirth only helps if the committee doesn't think less of a woman for taking that option - or doesn't assume that the woman should write twice as many papers in that time.

\section{Kim Hannula}

Department of Geoscience, Fort Lewis College, Durango, Colorado, USA

e-mail: hannula_k@fortlewis.edu 